\title{
Method of Ventral Hernia Repair: Our Experience
}

\author{
Ketul Shah', Ankur Jain ${ }^{2}$, Vipul Gurjar ${ }^{3}$, Anant Shah ${ }^{3}$ \\ ${ }^{1}$ Assistant Professor, ${ }^{2}$ PG Resident, ${ }^{3}$ Professor, Department of General Surgery, Dhiraj General Hospital, Smt. \\ B.K. Shah Medical Institute and Research Centre. Sumandeep Vidyspeeth Deemed to be University (An Institution), \\ Pipariya, Vadodara
}

\begin{abstract}
Background: Ventral hernias result from weakness in the musculofascial layer of the anterior abdominal wall. Ventral hernia can be operated through open or laparoscopic approach. Moreover, there are various options available for mesh placement during the repair. We here report our experience in surgical management of ventral hernias along with review of published literature along with laparoscopic repair of ventral hernias.

Method: It was a retrospective study of patients who were operated for ventral hernias over a period of 4 years in a teaching hospital of Vadodara SBKS research institute Dhiraj Hospital. All patients irrespective of age and sex were included. All patients were evaluated by obtaining proper history and performing detailed physical examination and routine blood investigations. Various intra operative and postoperative parameters were observed and reported.

Conclusions: The ventral hernia repair can be done by open and laparoscopic technique. Each has its own advantages and disadvantages. There is no conclusively guidelines about the superiority of one technique over the other and also no conclusively guidelines for the proper position of mesh placement. The clear advantages of open technique is avoidance of general anesthesia in many cases (as many ventral hernia repairs can be done under local anaesthesia), lesser learning curve, cheap meshes can be used, easy to learn, no requirement of any sophisticated instruments or OT setup and trained staff. The disadvantage of laparoscopic technique includes the requirement for general anaesthesia (as many ventral hernias can be performed with local anaesthesia in open technique), need to transverse the abdominal cavity, prolonged learning curves, requirement of costly meshes and sophisticated equipment and technical staff. However, laparoscopy has advantage over open hernia repair in terms of reduced postoperative pain, decreased postoperative complications, reduced length of hospital stays, less time for return to normal activity and bettercosmesis.
\end{abstract}

Keywords: Hernia repair, Incisional hernia, Laparoscopic, Open, Ventral hernia.

\section{Introduction}

Ventral hernia are happening because of shortcoming in the musculofascial layer of the foremost stomach

\section{Corresponding Author:}

\section{Dr. Ketul Shah}

Assistant Professor, Department of General Surgery, Dhiraj General Hospital, Smt. B.K Shah Medical Institute and Research Centre. Sumandeep Vidyspeeth Deemed to be University (An Institution), Pipariya, Vadodara

Phone: 9724507634 divider ${ }^{[1]}$. The evaluated occurrence of ventral hernia is $15-20 \%{ }^{[2]}$. They are grouped into incisional, umbilical, paraumbilical, epigastric and spigelian hernia ${ }^{[3,4]}$. Most normal are incisional hernia after a stomach activity ${ }^{[5]}$. It is assessed that $2-10 \%$ of every single stomach activity result in incisional hernia ${ }^{[2]}$. Essential tissue fix should be possible in little hernias ( $<2.5 \mathrm{cms}$ distance across). In any case, odds of repeat increments if essential tissue fix is accomplished for bigger hernias $(>2.5 \mathrm{cms}$ in breadth). Thusly, the possibility of strain free fix utilizing prosthetic work is generally acknowledged. Prosthetic work has diminished repeat to irrelevant rates. ${ }^{[6]}$.

For laparoscopic ventral hernia repair, the mesh 
is routinely placed in the intra-peritoneal position. However, for open surgery, there are numerous options for mesh placement [7]. Only repair places the mesh on the anterior fascia which typically involves the dissection of flaps and primary closure of the fascia below the mesh. Inlay repair places the mesh in the hernia defect and secure the mesh circumferentially to the edges of the fascia. Sublay repair refers to retro- rectus preperitoneal mesh placement. Finally in underlay repair mesh is placed in intraperitoneal position and secured to the anterior abdominal wall, a technique popularized with the advent of laparoscopy [7].

The ideal position for placement of mesh has not been conclusively established [8, 9]. Polypropylene mesh is regarded as the implant of choice for repairing abdominal wall defects [8, 10]. Here we report our experience in surgical management of ventral hernias. We also reviewed our results with other studies, along with laparoscopic repair of ventral hernias.

\section{Methodology}

It was a retrospective study of patients who were operated for ventral hernias over a period of 2.5 years in a teaching hospital of vadodra SBKS research institute Dhiraj Hospital. All patients irrespective of age and sex were included. All patients were evaluated by obtaining proper history and performing detailed physical examination and routine blood investigations. All patients received antibiotic prophylaxis half an hour before surgery. Most patients were operated under spinal anesthesia. Foleys catheterization and nasogastric tube were occasionally used. Anatomical repair was done for smaller hernias $(<2.5 \mathrm{cms}$ in diameter $)$ whereas mesh repair was done for larger hernias $(>2.5 \mathrm{cms}$ in diameter). In onlay repair, polypropylene mesh was sutured over the anterior rectus sheath, whereas in sublay technique, the mesh was placed in the preperitoneal space. The mesh was fixed with nonabsorbable sutures. Anterior rectus sheath was closed over the mesh by nonabsorbable sutures. Suction drain was placed based on the surgeon'schoice.

The patients were started on oral liquids 8 to 12 hours after the surgery in open mesh repair. Soft diet was started thereafter. Good analgesic coverage was provided with injection diclofenac/injection tramadol in early postoperative period which helped in early ambulation and recovery. Patients were encouraged for sitting up in the bed and advised early movements and activity. The wound was inspected for any seroma, hematoma, or infection. The drains were removed when the collection was less than $30 \mathrm{ml}$ for 2 consecutive days. Patients were discharged after complete ambulation and tolerating normaldiet.

\section{Results and Observations}

The study included 95 patients with 46 males (48.4 $2 \%$ ) and 49 females (51. 58\%) with male: female ratio of 1:1.07. The commonest type of hernias encountered were incisional hernias $(76.84 \%)$, followed by paraumbilical (11. 58\%), epigastric $(8.42 \%)$, umbilical $(3.16 \%)$ Table-1. The common index surgeries were gynecological and obstetrical surgeries

Table-1: Demographic parameters.

\begin{tabular}{|l|c|}
\hline Variables & $\begin{array}{c}\text { Open ventral hernia repair } \\
(\mathbf{n}=\mathbf{9 5})\end{array}$ \\
\hline Mean age (range) in years & $36.2(14-78)$ yrs \\
\hline Gender Distribution & \\
Males & $46(48.42 \%)$ \\
Females & $49(51.58 \%)$ \\
\hline Male : Female & $1: 1.07$ \\
\hline Types of hernia & \\
Umbilical & $3(3.16 \%)$ \\
Incisional & $73(76.84 \%)$ \\
Epigastric & $8(8.42 \%)$ \\
Paraumbilical & $11(11.58 \%)$ \\
Total & $\mathbf{9 5}(\mathbf{1 0 0} \%)$ \\
\hline
\end{tabular}

Table 2: Index of Surgery

\begin{tabular}{|l|c|}
\hline Index surgery & No. of Patients \\
\hline Peptic perforation & 11 \\
\hline Cholecystectomy (kocher's) & 7 \\
\hline Enteric perforation & 9 \\
\hline Tubercular perforation & 9 \\
\hline Ruptured liver abscess & 2 \\
\hline Prostatectomy & 2 \\
\hline Pyelolithotomy & 2 \\
\hline Appendectomy & 7 \\
\hline Hysterectomy & 10 \\
\hline Caesarean section & 8 \\
\hline Post-tubectomy & 4 \\
\hline Ovarian cystectomy & 2 \\
\hline Total & $\mathbf{7 3}$ \\
\hline
\end{tabular}


The mean size of defect was $3.36 \mathrm{~cm}^{2}$. The mean number of defects encountered were 1.4 (1-3). The content of most hernias was bowel loops (56. 84\%), followed by omentum (43.16\%). Anatomical repair was done in $18.95 \%$ of patients and mesh repair was done in $81.05 \%$ of patients. Polypropylene was used in all the cases. Onlay fixation was done in $67.53 \%$ and sublay in $32.47 \%$ patients. Suction drain was used in $85.26 \%$ patients. We met with single episode of accidental enterotomy (1.05\%) while dissection which was primarily closed, mesh was placed $\&$ postoperative period was unremarkable. The average operative time was98.30 minutes in our study Table-3.

Table-3: Intra-operative parameters

\begin{tabular}{|l|c|}
\hline Mean defect size & $\mathbf{3 . 3 6} \mathbf{c m}^{\mathbf{2}}$ \\
\hline No. of defects & $1.4(1-3)$ \\
\hline Contents of hernia & \\
Omentum & $41(43.16 \%)$ \\
Bowelloops & $54(56.84 \%)$ \\
\hline Technique of repair & \\
Anatomical & $18 / 95(18.95 \%)$ \\
Hernioplasty & $77 / 95(81.05 \%)$ \\
\hline Type of mesh used & Polypropylene \\
\hline Site of mesh placement & \\
Onlay & $52 / 77(67.53 \%)$ \\
sublay & $25 / 77(32.47 \%)$ \\
\hline Drain used (no. of patients) & $81 / 95(85.26 \%)$ \\
\hline Intra-operative complications & \\
Enterotomy & $1 / 95(1.05 \%)$ \\
\hline Operative time(in minutes) & $98.30 \mathrm{~min}$ \\
\hline
\end{tabular}

Table-4: Post-operative parameters.

\begin{tabular}{|l|c|}
\hline $\begin{array}{l}\text { Mean Analgesia required (in terms of no. } \\
\text { of times analgesic drug administered) }\end{array}$ & $\mathbf{6 . 4 ( 2 - 1 0 )}$ \\
\hline Post-operative complications. & $23 / 95,(24.21 \%)$ \\
\hline Overall & $9 / 95,(9.47 \%)$ \\
\hline Superficial woundinfection & $5 / 95,(5.26 \%)$ \\
\hline Deep woundinfection & $1 / 95,(1.05 \%)$ \\
\hline Meshinfection & $1 / 95,(1.05 \%)$ \\
\hline Flap necrosis & $7 / 95,(7.37 \%)$ \\
\hline Seroma & $4.22(1-18)$ \\
\hline Mean Post-operative hospital stay (in days) &
\end{tabular}

The average requirement of analgesia was 6.4 times in our study. Overall postoperative complication rate was $24.21 \%$. Most of them were superficial wound infections $(9.47 \%)$ and seroma formation $(7.37 \%)$. All of which were managed conservatively. One of the patient developed mesh infection, but it was successfully managed with regular wound toileting with betadine, hydrogen peroxide and metrogyl-soaked gauze packing of the wound. The mean length of the post-operative hospital stay was 4.22 days (1-18 days) (table 4$)$.

"The overall recurrence rate was $7.37 \%$ in our study at an average follow-up period of 12.02 months (3-28 months)". Anatomical repair showed more recurrence rate $(22.22 \%)$ than those with mesh hernioplasty (3.9\%) Table-5.

\section{Table-5: Follow-up and recurrences}

\begin{tabular}{|l|c|}
\hline Follow-up (in months) & $\mathbf{1 2 . 0 2 ( 3 - 2 8 ~ m o n t h s )}$ \\
\hline Recurrence rate & \\
Overall & $7 / 95(7.37 \%)$ \\
Anatomicalrepair & $4 / 18(22.22 \%)$ \\
Hernioplasty & $3 / 77(3.90 \%)$ \\
\hline
\end{tabular}

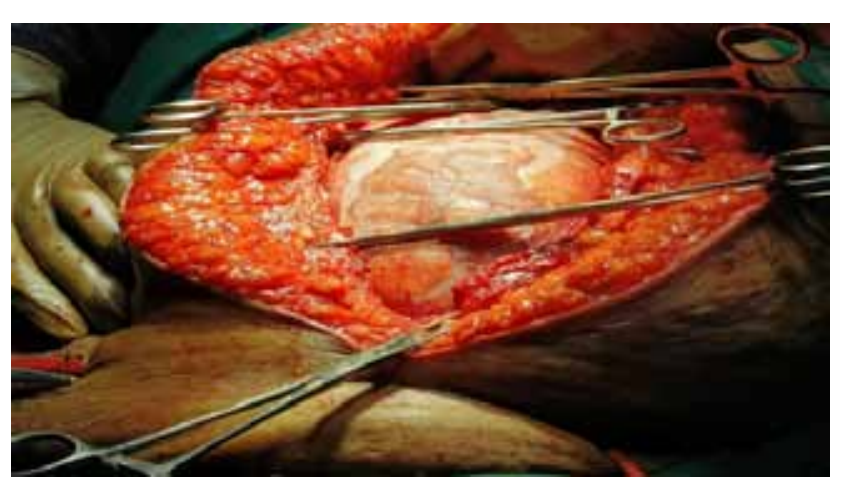

Figure 1: Onlay repair with suction drain

\section{Discussion}

Ventral hernia in the anterior abdominal wall includes both spontaneous and most commonly, incisional hernia after an abdominal surgery ${ }^{5}$. Since the success of hernia repair surgery is usually reflected in terms of hernia recurrence after the repair, hernia recurrence is distressing to the patient and embarrassing to surgeons. The use of prosthetic mesh has revolutionized the field of hernia repair by providing tension free repair. More recently with introduction of laparoscopy in the field of surgery, the trend of laparoscopic ventral hernia repair is on rise. But with disadvantages of requirement for general anesthesia (as many ventral hernias can be performed with local anesthesia in open technique), need to transverse the abdominal cavity, prolonged learning curves, requirement of costly meshes and sophisticated equipment and technical staff makes laparoscopic hernia repair account for minority of cases performed 
worldwide [11]. However, laparoscopy has advantage over open hernia repair in terms of reduced postoperative pain, decreased postoperative complications, reduced length of hospital stay, less time for return to normal activity and bettercosmesis ${ }^{12}$.

The present study consisted of 95 patients, 46 males and 49 females with male: female ratio of 1:1.07. The commonest index surgery reported was gynaecological/ obstetrical operation. Most common site of ventral hernia was lower abdominal, again reflecting higher incidence of gynaecological obstetricaloperation. The. mean.surgerytime.in.our.study.was 98.30minutes, whichislongerthanthatpublishedin literature for laparoscopic ventral hernia repair surgery, which reflects the more time involved in dissection and securing haemostasis (95 minutes in Park et al., ${ }^{[13]}, 87$ minutes in Carbajaet al., ${ }^{[14]}, 56$ minutes in Rameshawet al.., ${ }^{[15]}, 55$ minutes in Badiger $\mathrm{S}$ et al., ${ }^{[16]}$. With respect to intraoperative complications, there was single episode of inadvent enterotomy while dissection which was primarily closed as it involved no spillage, mesh was placed and later postoperative period was uneventful.

The overall incidence of wound infection in our study was $24.21 \%$. Since the amount of tissue dissection needed in open ventral hernia repair is more, the chances of wound related complications is more. Such complications are lower in laparoscopic ventral hernia repair as it does not need much of abdominal wall dissection. Most of the wound infections can be managed conservatively by local wound toilets and antibiotics. Removal of mesh is rarely required. For open mesh repair, the wound related complications range from $3.5 \%-18 \%{ }^{[17-29]}$, with an average of $8.1 \%$; whereas for laparoscopic repair it is overall $2 \%{ }^{[11,17]}$.

The average number of times the analgesic drug administered in our study was 6.4. The literature [11, 17] reported a lower rate of requirement for analgesia in laparoscopic hernia repair than open technique as it involves lesser tissue dissection and avoidance of sutures as done in open ventral hernia repair. For the similar reason the early ambulation and hospital stay is prolonged in open ventral hernia repair then in laparoscopic repair.

Our study reported an average of 4.22 days as mean length of postoperative hospital stay for open ventral hernia repair. Syed JF Qadriet al., ${ }^{[17]}$ reported

1.53 days as mean hospital stay in laparoscopic incisional hernia repair group compared to 4.33 days in open hernia repair group. Similarly, Park et al., [14] reported 3.4 days for laparoscopic repair group and 6.5 days for open hernia group; Rameshawet al., ${ }^{[15]}$ reported 1.7 days for laparoscopic repair group and 2.8 days for open hernia repair; and Badiger $\mathrm{S}$ et al., ${ }^{[16]}$ reported 2.6 days for laparoscopic repair group and 6.8 days for open repair group.

In various studies of open and laparoscopic incisional hernia repair, the recurrence rate reported is 0-12.5\%.for.laparoscopic.repair,.with.an.average.of

$5.97 \%$; and $0-13 \%$ for open technique, 17 an average of $6.22 \%{ }^{[12]}$. Ramshaw et al., reported a recurrence rate of $7 \%$ in open group and $0 \%$ in laparoscopic group at an average follow up for 21 months for each group. Pringet $a l$. , reported a recurrence rate of 4.16 in open group and $3.3 \%$ in laparoscopic.group.at an average.follow-up. period.of

27.5 months for each group. Itaniet al., reported a recurrence rate of $8.2 \%$ in open group and $12.5 \%$ in laparoscopic group at an average follow-up period of 24 months Thota et al., ${ }^{[12]}$ reported a recurrence rate of $0 \%$ in both open and laparoscopic repair group at an average follow-up period of 13.25 months in open group and 10.55 months laparoscopicgroup.

\section{Conclusion}

Thus, in conclusion, the ventral hernia repair can be done by open and laparoscopic technique. Each has its own advantages and disadvantages. There is no conclusively guidelines about the superiority of one technique over the other and also no conclusively guidelines for the proper position of mesh placement. It was rightly mentioned in Author's previous article ${ }^{[11]}$ that surgeons should not perform laparoscopic hernia procedure simply because it is relatively new or potentially economic; they should perform only when convinced that it is anatomically and physiologically correct and logical. Surgeons must be proficient in laparoscopic techniques and must have a precise knowledge of anatomy.

The advantages of open technique is to avoid of general anaesthesia in many cases (as many ventral hernia repairs could be done under local anaesthesia), lesser learning curve, cheap meshes can be used, easy to learn, no requirement of any sophisticated instruments or OT setup and trained staff. The disadvantage of laparoscopic technique includes the requirement for 
general anaesthesia (as many ventral hernias can be performed with local anaesthesia in open technique), need to transverse the abdominal cavity, prolonged learning curves, requirement of costly meshes and sophisticated equipment and technical staff. However, laparoscopy has advantage over open hernia repair in terms of reduced postoperative pain, decreased postoperative complications, reduced length of hospital stay, less time for return to normal activity and better cosmesis.

Ethical Clearance: Taken from sumandeepvidyapeeth institutional ethics committee

\section{Source of Funding: Self}

Conflict of Interest: Nil.

\section{References}

1. Stumpf M, Conze J, Klinge U, Rosch R, Schumpelick V. Open mesh repair. Eur Surg. 2003;35(1):21-24.

2. de Vries Reilingh TS, van Geldere D, Langenhorst $\mathrm{BL}$, de Jong $\mathrm{D}$, van der Wilt GJ, van Goor $\mathrm{H}$, Bleichrodt RP. Repair of large midline incisional hernias with polypropylene mesh:comparison of three operative techniques. Hernia. $2004 \mathrm{Feb}$ 1;8(1):56-9.

3. Holihan JL, Nguyen DH, Nguyen MT, Mo J, Kao LS, Liang MK. Mesh location in open ventral hernia repair: a systematic review and network meta-analysis. World journal of surgery. 2016 Jan 1;40(1):89-99.

4. Raghuveer MN, Muralidhar S, Shetty H, Veena V. Onlay versus sublay mesh repair for ventral. hernia. International Surgery Journal. 2018 Feb 26;5(3):823-6.

5. Strâmbu V, Radu P, Bratucu M, Garofil D, Iorga C, Iorga R, Popa F. Rives technique, a gold standard for incisional hernias-our experience. Chirurgia (Bucur). 2013 Jan1;108(1):46-50.

6. Petro CC, Posielski NM, Raigani S, Criss CN, Orenstein SB, Novitsky YW. Risk factors for wound morbidity after open retromuscular (sublay) hernia repair. Surgery. 2015 Dec 1;158(6):1658-68.

7. Naikoo GM, Singh B, Jeelani Shaukat, Rajput N, Sofi IA, Choudhary MH, Banotra A. Open And Laparoscopic Inguinal Hernia Repair: Our Experience. IJSR; 2018May;7(5):3-4.
8. Thota A, Ravishankar KS, Rao KV, Ramesh BS, Ananda BB. Comparative study between open and laparoscopic ventral hernia repair: A prospective non-randomized single institutional study. Journal of Dr. NTR University of Health Sciences. 2017 Oct1;6(4):217-23.

9. Park A, Birch DW, Lovrics P. Laparoscopic and open incisional hernia repair: a comparison study. Surgery. 1998 Oct 1;124(4):816-22.

10. Carbajo MA, Del Olmo JM, Blanco JI, De la Cuesta C, Toledano M, Martin F, Vaquero C, Inglada L. Laparoscopic treatment vs open surgery in the solution of major incisional and abdominal wall hernias with mesh. Surgical endoscopy. 1999 Mar1;13(3):250-252.

11. Ramshaw BJ, Esartia P, Schwab J, Mason EM. Comparison of laparoscopic and open ventral herniorrhapy. The American Surgeon. 1999 Sep 1;65(9):827-31.

12. Badiger S, Koppad SN, Kulkarni A, Kodliwadmath H. Comparative analysis of open versus laparoscopic ventral hernia repair. International Surgery Journal. 2016 Dec 9;3(3):1167-72.

13. Qadri SJ, Khan M, Wani SN, Nazir SS, Rather A. Laparoscopic and open incisional hernia repair using polypropylene mesh-A comparative single centre study. International Journal of Surgery. 2010 Jan1;8(6):479-83.

14. Carbajo MA, Del Olmo JM, Blanco JI, De la Cuesta C, Toledano M, Martin F, Vaquero C, Inglada L. Laparoscopic treatment vs open surgery in the solution of major incisional and abdominal wall hernias with mesh. Surgical endoscopy. 1999 Mar 1;13(3):250-252.

15. Ramshaw BJ, Esartia P, Schwab J, Mason EM. Comparison of laparoscopic and open ventral herniorrhapy. The American Surgeon. 1999 Sep 1;65(9):827-31.

16. Badiger S, Koppad SN, Kulkarni A, Kodliwadmath H. Comparative analysis of open versus laparoscopic ventral hernia repair. International Surgery Journal. 2016 Dec 9;3(3):1167-72.

17. Qadri SJ, Khan M, Wani SN, Nazir SS, Rather A. Laparoscopic and open incisional hernia repair using polypropylene mesh-A comparative single centrestudy.International Journal of Surgery. 2010 Jan 1;8(6):479-83AA 